\title{
Glycogen storage disease with severe cardiomyopathy due to glycogenin deficiency
}

INSERM

\section{Source}

INSERM. (1999). Orphanet: an online rare disease and orphan drug data base. Glycogen storage disease with severe cardiomyopathy due to glycogenin deficiency.

ORPHA:263297

Glycogen storage disease type 15 is an extremely rare genetic glycogen storage disease reported in one patient to date. Clinical signs included muscle weakness, cardiac arrhythmia associated with accumulation of abnormal storage material in the heart and glycogen depletion in skeletal muscle. 